\title{
Profiling the Yeast Communities of Wine Fermentations Using Terminal Restriction Fragment Length Polymorphism Analysis
}

\author{
Nicholas A. Bokulich, ${ }^{1}$ Chin-Feng Hwang, ${ }^{2,5}$ Shuwen Liu, ${ }^{6}$ \\ Kyria L. Boundy-Mills, ${ }^{3}$ and David A. Mills ${ }^{4 *}$
}

\begin{abstract}
Terminal restriction fragment length polymorphism (TRFLP), used most often to describe bacterial communities, presents a high-throughput, low-cost solution for analyzing mixed yeast communities in wine and other fermentations. In this study, a TRFLP approach was developed for the identification and discrimination of yeasts and used to construct a TRFLP database comprising 121 strains of yeast (representing 24 genera and 72 species) associated with wine and food fermentations. This database exhibits sensitive discrimination among species and robust intraspecific conservation of TRFLP profiles, enabling reliable characterization of mixed yeast communities. The yeast ecology of sweet, botrytized wine fermentations from two separate vintages was analyzed using this database, demonstrating the utility of this method for fast-paced, qualitative detection and identification of differences in yeast community structures over time in a complex, diverse fermentation system.
\end{abstract}

Key words: TRFLP, culture-independent methods, community profiling

Wine fermentations typically involve a complex, multispecies consortium of yeasts. The most important are Saccharomyces species, but yeasts of the genera Hanseniaspora, Kluyveromyces, Metchnikowia, Candida, Zygosaccharomyces, Brettanomyces, and many others are often present and active at different stages of the fermentation, introduced either from grape surfaces or from the winery environment (Boulton et al. 1996). Most of these yeasts are considered beneficial or benign, but several are among the most destructive contaminants in the wine industry, spoiling wines through the production of off-flavors, haze/films/sediment, or gas production (Boulton et al. 1996). Thus, characterizing these communities requires techniques that enable rapid, sensitive discrimination of yeast species in musts and wines.

${ }^{1}$ Graduate Researcher, ${ }^{2}$ Assistant Specialist, ${ }^{3}$ Specialist, and ${ }^{4}$ Professor, Department of Viticulture and Enology, Robert Mondavi Institute for Wine and Food Science, University of California, Davis, CA 95616; ${ }^{5}$ Associate Professor, Missouri State Fruit Experiment Station, William H. Darr School of Agriculture, Missouri State University, Mountain Grove, MO 65711; and ${ }^{6}$ Professor, College of Enology, Northwest Sci-Tech University of Agriculture and Forestry, Yanling, Shaanxi, China.

*Corresponding author (damills@ucdavis.edu)

Acknowledgments: This work was supported in part by grants from the Oregon Wine Board and the California Competitive Grants Program for Research in Viticulture and Enology to DM. NB was supported in part by the D.E. Gallo educational enhancement fund, A.L. \& R.C. Heck research fellowship, Wine Spectator scholarship, R.C. Briess scholarship, M.J. Lewis endowment, and Jastro \& Shields fellowship. KBM was supported in part by NIH award 1U01TW008160 and USDA-AFRI 2008-35621-04750.

The authors thank Greg Allen (Dolce Winery, Oakville, CA) for the generous contribution of wine samples and critical review of the manuscript.

Manuscript submitted Aug 2011, revised Sept 2011, accepted Nov 2011. Publication costs of this article defrayed in part by page fees.

Copyright $(92012$ by the American Society for Enology and Viticulture. All rights reserved.

doi: 10.5344/ajev.2011.11077
Traditionally, culture-based enrichment methods are used for detection and identification of yeasts in wine, but these methods can be time-consuming and can misrepresent the community present by biasing for the growth of less fastidious organisms (Heard and Fleet 1986), and the occurrence of viable-but-not-culturable (VBNC) cells in the low-pH, highethanol environment of wine can limit the sensitivity of these methods (Millet and Lonvaud-Funel 2000). To surmount these issues, culture-independent methods for comprehensively profiling wine microbiota have received more attention, with denaturing gradient gel electrophoresis (DGGE) the most popular (Cocolin et al. 2000, 2001, Mills et al. 2002). However, community profiling using DGGE is complicated by a number of technical issues related to gel-based separation (Nubel et al. 1996, Sekiguchi et al. 2001, Kisand and Wikner 2003), but above all DGGE is a technically challenging method that requires a high level of skill and ultimately only separates different strands, necessitating a gel extraction/sequencing step to complete identification. These issues limit the application of this technique in situations that require high-throughput processing of large and ecologically diverse sample sets, such as multivintage, multitreatment studies of wine fermentations.

Terminal restriction fragment length polymorphism (TRFLP) is another culture-independent profiling method that, like DGGE, has become popular for characterizing complex environmental communities. This method (Figure 1) enables sensitive discrimination of mixed microbiota based on restriction site heterogeneity of hypervariable DNA sequences (most typically rRNA genes) amplified using fluorescently labeled PCR primers. As only the terminal fragments retain the fluorescent tag, each organism present should be represented by one fluorescent peak. However, fragment size parity among taxonomically similar organisms for a given restriction enzyme can complicate identification (Liu et al. 1997), 


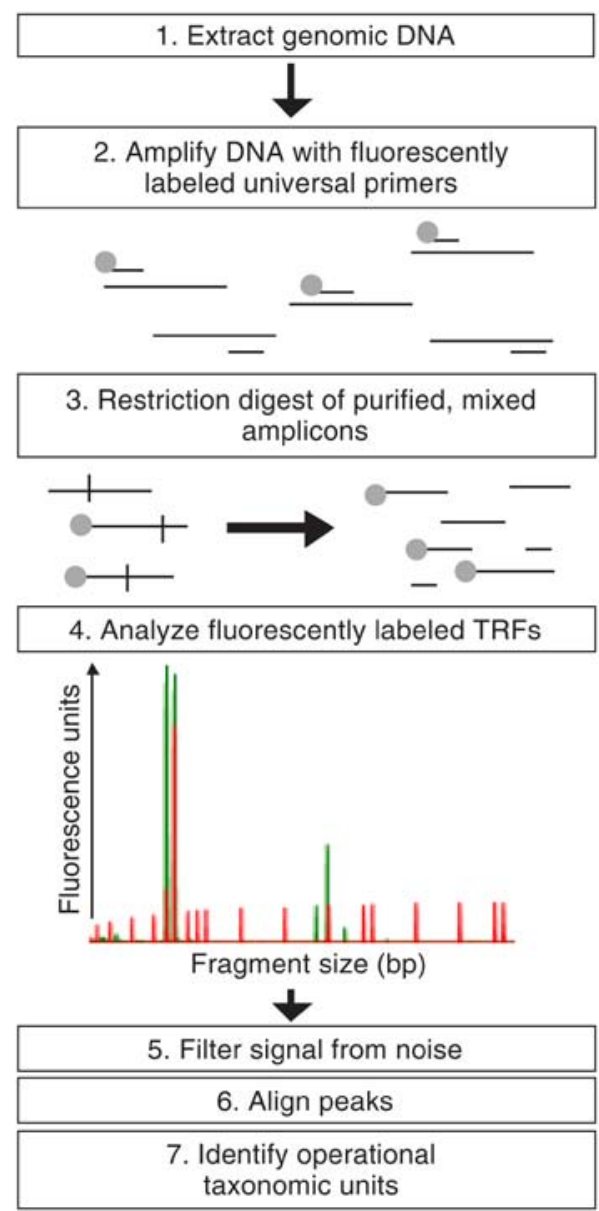

Figure 1 Process flow schematic for terminal restriction fragment length polymorphism.

and in practice these are grouped as operational taxonomic units (OTU) matching the terminal restriction fragment (TRF) profile. TRFs are compared to a database of known TRF profiles to unravel community structure. For identifying bacteria, this database is most commonly derived by in silico digests of 16S rRNA sequences deposited in public databases. However, studies that use TRFLP to describe complex fungal communities in soils and other environments (e.g., Adams Krumins et al. 2009, Edwards and Zak 2010, Macdonald et al. 2008) have instead relied on TRFLP as a tool to describe large-scale shifts in fungal diversity as observed by changes in TRF profiles, but not for identification of individual OTUs against a reference database, providing specific community structure information. That is partly due to the paucity of complete fungal sequence data deposited in public databases, making putative identification of most OTUs impossible. Nor does a comprehensive fungal TRFLP database exist, which would provide more reproducible identification of OTUs, because of the variability of restriction sites among members of the same genus/species (Anderson and Cairney 2004). Thus, the creation of a robust TRFLP database is essential for the adoption of this technique to study fungal communities.

TRFLP presents a promising solution for community profiling in wine with the following advantages over other profiling techniques: (1) it is adapted for high-throughput sample processing and thus can describe variation in large time-based and multivariate-treatment-based studies; (2) it is a robust, sensitive method that does not require additional sequencing steps following OTU separation (as with DGGE); and (3) it is a low-cost, relatively low-tech method providing fairly sensitive data when characterizing communities with low-to-moderate diversity, such as wine and food fermentations. TRFLP is not a perfect method, and as with any PCRbased method there are potential limitations of primer binding bias (Leuders and Friedrich 2003), operon copy number heterogeneity (Crosby and Criddle 2003), and polymerase error (Osborn et al. 2000), although many of these issues can be ameliorated by procedural modification (Polz and Cavanaugh 1998, Osborn et al. 2000). When conducted with appropriate methodological and statistical treatment, TRFLP has been shown to yield reliable, accurate, pseudo-quantitative representations of complex microbial community structure (Blackwood et al. 2003, Leuders and Friedrich 2003, Liu et al. 1997, Osborn et al. 2000, Schutte et al. 2008, Trotha et al. 2002).

However, there are no studies to date that have considered TRFLP for analysis of wine/food fermentation microbial ecology or that have developed/optimized a method for characterization of yeast ecology of wine/food microbial communities using TRFLP. For the purposes of this study, a yeast TRFLP profile database was generated from 121 different strains of yeast (representing 24 genera and 72 species) common in wines and fermented foods. This database was created targeting the internal transcribed spacer (ITS) region of the fungal rRNA gene. This noncoding spacer region is one of the most frequently chosen molecular targets for identifying fungi because of its polymorphism, allowing for subtle differentiation of species (Gardes and Bruns 1993). Method robustness was assessed by testing TRFLP profile consistency among six strains of Saccharomyces cerevisiae and nine of Candida zemplinina and the detection threshold for minority species in mixed culture titrations. The yeast ecology of sweet, botrytized wine fermentations was then analyzed using this database and results for specific populations validated by quantitative PCR (qPCR). Results demonstrate the utility of TRFLP for characterizing the yeast communities present in wine fermentations with a high degree of sensitivity.

\section{Materials and Methods}

DNA extraction. Must/wine samples collected from Dolce Winery (Oakville, CA) were immediately frozen on site, transported on ice, and stored at $-80^{\circ} \mathrm{C}$ until processing. Two separate vintages were sampled: 2008 (inoculated with S. cerevisiae), sampled directly from the press pan (day 0 ) and after 1, 6, 19, and 51 days of fermentation, and 2009 (native fermentation), sampled directly from the press pan (day 0 ), and after $6,9,10,17,21,26,32,38,49,59$, and 66 days of fermentation. Frozen samples were thawed and centrifuged at $8,000 \times g$ for $15 \mathrm{~min}$ and decanted, retaining the cell pellet, which was processed immediately. All wine samples were extracted and analyzed in duplicate.

Pure yeast cultures used for construction of the ITS TRFLP database were obtained from the Phaff Yeast Culture 
Collection, University of California (UC) Davis, and the Viticulture and Enology Culture Collection, UC Davis, and grown in YEPD (1\% [wt/vol] yeast extract, 2\% [wt/vol] peptone, and $2 \%$ [wt/vol] glucose) at room temperature. Whole cultures were centrifuged at $8,000 \times g$ for $15 \mathrm{~min}$ and decanted, retaining the cell pellets, which were stored at $-80^{\circ} \mathrm{C}$ until processing.

From the resulting cell pellet, $100 \mu \mathrm{L}$ were washed three times by suspension in $1 \mathrm{~mL}$ ice-cold PBS, centrifugation at $8,000 \times g(5 \mathrm{~min})$, and the supernatant discarded. The pellet was then suspended in $200 \mu \mathrm{L}$ DNeasy lysis buffer $(20 \mathrm{mM}$ Tris-Cl [pH 8.0], 2 mM sodium EDTA, 1.2\% Triton X-100) supplemented with $40 \mathrm{mg} / \mathrm{mL}$ lysozyme and incubated at $37^{\circ} \mathrm{C}$ for $30 \mathrm{~min}$. From this point, the extraction proceeded following the protocol of the Qiagen Fecal DNA Extraction Kit protocol (Qiagen, Valencia, CA), with the addition of a bead-beater cell lysis step of 2 min at maximum speed following addition of "buffer ASL" using a FastPrep-24 bead-beater (MP Biomedicals, Solon, OH). DNA extracts were stored at $-20^{\circ} \mathrm{C}$ until further analysis.

TRFLP. PCR amplification was performed in $50 \mu \mathrm{L}$ reactions containing 5 to $100 \mathrm{ng} / \mu \mathrm{L}$ of DNA template, $25 \mu \mathrm{L}$ 2X Promega GoTaq Green Master Mix (Promega, Madison, WI), $1 \mathrm{mM} \mathrm{MgCl}$, and 2 pmol of each primer. Each PCR was performed in triplicate and the products combined prior to purification to limit the potential for PCR amplification bias.

For amplification of the ITS1/ITS4 domain, the forward primer used was ITS1HEX (5'-[5HEX] TCCGTAGGTGAACCTGCGG-3') and the reverse primer was ITS4 (5'-TCCTCCGCTTATTGATATGC-3') (White et al. 1990). PCR conditions were an initial denaturation at $95^{\circ} \mathrm{C}$ for 2 min, followed by 30 cycles of denaturation at $95^{\circ} \mathrm{C}$ for $1 \mathrm{~min}$, annealing at $50^{\circ} \mathrm{C}$ for $1 \mathrm{~min}$, and extension at $72^{\circ} \mathrm{C}$ for 2 min, with a final extension at $72^{\circ} \mathrm{C}$ for $7 \mathrm{~min}$. All amplifications were performed in a Veriti Thermal Cycler (Applied Biosystems, Foster City, CA). PCR products were analyzed by electrophoresis on a $1 \%(\mathrm{wt} / \mathrm{vol})$ agarose gel in $1 \mathrm{X}$ TAE stained with Gel Red (Biotium, Hayward, CA) and visualized under UV light. A 100-bp DNA ladder (New England BioLabs, Ipswich, MA) was used as a size standard. All PCR products were purified using QIAquick PCR Purification Kit (Qiagen), following the manufacturer's instructions.

Purified PCR products were digested using the restriction enzymes HaeIII, DdeI, and HinfI. The digested DNA was submitted to the UC Davis College of Biological Sciences Sequencing Facility. Traces were visualized using Peak Scanner Software v1.0 (Applied Biosystems) using a baseline detection value of 10 fluorescence units. Peak filtration and clustering was performed with R software (http://www.R-project.org/) using the program scripts and statistical analysis protocols designed by Abdo et al. (2006).

The TRF profiles of the pure yeast cultures were used to create the ITS TRFLP database (Table 1). Putative species assignments of the unknown fragments in the wine must samples were then made by referencing this ITS database. TRF profile consistency was tested by analyzing six strains of $S$. cerevisiae and nine of $C$. zemplinina. TRFLP detection sensitivity was tested by analyzing mixtures containing decreasing concentrations of Pichia membranifaciens titrated against a known, constant concentration of $S$. cerevisiae.

Quantitative PCR. Quantitative PCR was performed in $20-\mu \mathrm{L}$ final volume reactions containing $2 \mu \mathrm{L}$ DNA template, $0.2 \mu \mathrm{M}$ each respective primer, and $10 \mu \mathrm{L}$ Takara SYBR 2X Perfect Real Time Master Mix (Takara Bio Inc., Otsu, Japan). The primers YEASTF (5'-GAGTCGAGTTGTTTGGGAATGC-3') and YEASTR (5'-TCTCTTTCCAAAGTTCTTTTCATCTT-3'), producing a 124-bp fragment, were used to enumerate total yeast (Hierro et al. 2006). Reaction conditions involved an initial step at $95^{\circ} \mathrm{C}$ for $10 \mathrm{~min}$, followed by 40 cycles of $15 \mathrm{sec}$ at $95^{\circ} \mathrm{C}, 1 \mathrm{~min}$ at $60^{\circ} \mathrm{C}$, and $30 \mathrm{sec}$ at $72^{\circ} \mathrm{C}$, followed by a melt curve to assess amplicon specificity. Cell concentration was calculated by comparing sample threshold values $\left(C_{T}\right)$ to a standard curve of serially diluted genomic DNA extracted from a known concentration of $S$. cerevisiae. The primers $\mathrm{SC1}$ (5'-GAAAACTCCACAGTGTGTTG-3') and SC2 (5'-GCTTAAGTGCGCGGTCTTG-3') were used to enumerate total Saccharomyces present, and the primers CZ2 (5'CTTGGGTGTCGAAAGGCG-3') and CAST (5'-CAATATGCGTTCAAAAATTCAAT-3') for Candida zemplinina (Zott et al. 2010). Reaction conditions involved an initial step at $95^{\circ} \mathrm{C}$ for $10 \mathrm{~min}$, followed by 40 cycles of $15 \mathrm{sec}$ at $95^{\circ} \mathrm{C}$, $1 \mathrm{~min}$ at $63^{\circ} \mathrm{C}(\mathrm{S}$. cerevisiae $)$ or $62^{\circ} \mathrm{C}(\mathrm{C}$. zemplinina $)$, and $30 \mathrm{sec}$ at $72^{\circ} \mathrm{C}$, followed by a melt curve to assess amplicon specificity. Cell concentration was calculated by comparing sample threshold values $\left(C_{T}\right)$ to a standard curve of serially diluted genomic DNA extracted from a known cell concentration of $S$. cerevisiae or C. zemplinina.

All reactions were performed in triplicate in optical-grade 96-well plates on an ABI Prism 7500 Fast Real-Time PCR System (Applied Biosystems). The instrument automatically calculated cycle threshold $\left(C_{T}\right)$, efficiency $(E)$, and confidence intervals.

\section{Results}

One of the main goals of this work was to develop a TRFLP database specifically targeted for wine and food yeast discrimination. The TRF profiles for 121 yeast strains were compiled to develop the yeast TRFLP database (Table 1). This database presents the TRF sizes resulting from each restriction digest for each yeast species. Where multiple TRF sizes exist for a single species (e.g., due to heterogeneity among multiple ITS copies within the yeast genome), values given in boldface type indicate the major (i.e., most abundant) TRF size for a given cut. To use the database, sample TRF sizes from each restriction digest are compared to the appropriate column. A species is considered "present" if all the corresponding major TRFs are found in a sample. Minor TRFs appearing for each yeast are provided in the database to aid filtration of these supplemental peaks from true, unknown TRFs and to limit the overestimation of sample diversity. The presence of these minor TRFs should not hinder data processing, as in most cases they do not match the major TRF sizes of other yeasts in the database, so remain unique. Additionally, these minor TRFs 
188 - Bokulich et al.

Table 1 Wine yeast internal transcribed spacer terminal restriction fragment database.

\begin{tabular}{|c|c|c|c|c|}
\hline Yeast & Strain $^{a}$ & Haelll & Hinfl & Ddel \\
\hline Brettanomyces anomalus & VEN2066 & $405^{b}, 375$ & 218, 437 & 435 \\
\hline Brettanomyces bruxellensis & $04-212$ & 368 & 203 & 462 \\
\hline Brettanomyces custersianus & VEN2027 & 442,408 & 208, 193, 442 & 443 \\
\hline Brettanomyces/Dekkera anomalus/anomala & VEN2826 & 407 & 220 & 437 \\
\hline Brettanomyces/Dekkera bruxellensis & VEN2079 & $367,341,462$ & 202, 461 & 462,427 \\
\hline Brettanomyces/Dekkera bruxellensis & VEN2807 & $367,341,461$ & $205,190,461$ & 462,427 \\
\hline Candida apicola & $69-111$ & 400 & $221,230,341,454$ & 454, 417 \\
\hline Candida boidinii & $72-163$ & 690,636 & 383 & 691,637 \\
\hline Candida bombi & 54-194 & 369,396 & 202,218 & 452,418 \\
\hline Candida carphphila & $74-101$ & 112 & 281 & 390 \\
\hline Candida ethanolica & 81-102 & 276,297 & 195 & 251 \\
\hline Candida guilliermondii & $65-4$ & 112,103 & 281 & $389,214,44$ \\
\hline Candida krusei & $40-371$ & 372 & 213 & 499 \\
\hline Candida krusei & $40-274$ & 370 & 213 & 498 \\
\hline Candida lactis-condensi & 68-139- & 405 & 232 & 59 \\
\hline Candida lipolytica & $79-100.4$ & 357 & 170 & 357 \\
\hline Candida maritima & $68-692.2$ & $568,401,523,649$ & $316,193,225,293$ & $197,181,495$ \\
\hline Candida oleophila & $62-4$ & 129 & 307 & 112 \\
\hline Candida oleophila & $68-35$ & 120,129 & 307 & 112,613 \\
\hline Candida sake & $51-18$ & 402,435 & 204 & 90 \\
\hline Candida salmanticensis & $71-181$ & 420 & 420 & 421 \\
\hline Candida solani & $51-36$ & 619,547 & 276 & 129 \\
\hline Candida stellata & $59-13$ & $401,371,455$ & 220,204 & 455,419 \\
\hline Candida tropicalis & 54-195 & 441,406 & 250 & 405 \\
\hline Candida versatilis & $51-32$ & 417,454 & 232 & 456 \\
\hline Candida zemplinina & $72-1034$ & 457 & 231 & 59 \\
\hline Candida zemplinina & VEN2097 & 456,422 & $234,214,454$ & 60,457 \\
\hline Candida zeylanoides & $40-019$ & $129,119,553$ & 307 & 112,415 \\
\hline Candida zeylanoides & $62-1033$ & $129,119,98,554$ & $300,224,316$ & $106,94,416$ \\
\hline Clavispora lusitaniae & $80-84$ & 377 & 177 & 377 \\
\hline Cryptococcus kuetzingii & 68-196 & 456,498 & 267 & 97 \\
\hline Cryptococcus laurentii & $76-106$ & 531 & 50 & 371 \\
\hline Cyberlindnera veronae & $68-1000.1$ & $125,115,530$ & $296,235,274,305,608$ & $32,83,610$ \\
\hline Debaryomyces hansenii var. hansenii & $40-56$ & 124,134 & 313 & 420 \\
\hline Debaryomyces hansenii var. hansenii & $40-59$ & $123,134,569$ & 313 & 420 \\
\hline Debaryomyces pseudopolymorphus & $57-3$ & $136,126,566$ & $301,227,316$ & $417,241,392$ \\
\hline Dekkera bruxellensis & $82-30$ & 365 & 202 & 461 \\
\hline Dekkera bruxellensis & 77-105 & $110,341,366$ & 204 & 461 \\
\hline Hanseniaspora guilliermondii & $40-023$ & 809 & 154 & 158 \\
\hline Hanseniaspora guilliermondii & 05-782 & 807,274 & $153,143,215,566$ & 157,521 \\
\hline Hanseniaspora uvarum & 54-192 & 802 & 153 & 157,444 \\
\hline Hanseniaspora uvarum & $55-310$ & 805,271 & $153,140,214,402$ & $157,88,444$ \\
\hline Hanseniaspora valbyensis & $68-28$ & 500,793 & $131,160,401$ & 125,135 \\
\hline Issatchenkia occidentalis & $75-63$ & 274,299 & $87,197,443$ & 409,443 \\
\hline Issatchenkia occidentalis & $52-171$ & 273,295 & 178,192 & 249 \\
\hline Issatchenkia orientalis & $05-784$ & 373,348 & $\mathbf{2 1 5}, 197,343,350$ & 499,462 \\
\hline Issatchenkia terricola & $99-57.1$ & 262,282 & 88 & 381,411 \\
\hline Issatchenkia terricola & $56-108$ & 282 & 87 & 412 \\
\hline Kloeckera apiculata & $94-155$ & 271,315 & 153,401 & 157,443 \\
\hline Kluyveromyces dobzhanskii & $50-45$ & 70 & 99,344 & 555 \\
\hline Kluyveromyces dobzhanskii & $51-200$ & 70,65 & 76,344 & 556 \\
\hline Kluyveromyces lactis & $72-12$ & 70 & 56 & $554,454,500,274$ \\
\hline Kluyveromyces lactis var. lactis & $70-4$ & 70 & $52,56,342$ & 554 \\
\hline Kluyveromyces marxianus & $40-351$ & 70 & 55 & 554 \\
\hline Kluyveromyces marxianus & $50-84$ & 70 & 56 & 553 \\
\hline Kluyveromyces thermotolerans & $55-41$ & 78,171 & 336 & 442,488 \\
\hline Kluyveromyces thermotolerans & $40-185$ & 79 & 336 & 488 \\
\hline Kluyveromyces waltii & $72-13$ & 79 & 336 & 488 \\
\hline Kluyveromyces waltii & $72-42$ & 79 & 336,95 & 488 \\
\hline Lachancea thermotolerans & $51-208$ & 79,171 & 336 & 488 \\
\hline Lanchanea thermotolerans & $40-193$ & 79 & 337 & 488 \\
\hline
\end{tabular}




\begin{tabular}{|c|c|c|c|c|}
\hline Yeast & Strain ${ }^{a}$ & HaellI & Hinfl & Ddel \\
\hline Metschnikowia pulcherrima & $40-118$ & 277 & 174 & 375 \\
\hline Metschnikowia pulcherrima & $60-317$ & 253,273 & 172 & 372 \\
\hline Pichia angophorae & $65-106$ & 668 & $396,168 ?$ & 186 \\
\hline Pichia angophorae & $65-106.3$ & 668,185 & $395,368,404$ & 185,173 \\
\hline Pichia anomala & $78-6$ & 658 & 296 & 432,394 \\
\hline Pichia anomala & $40-128$ & 655 & 297 & 433 \\
\hline Pichia burtonii & $76-51$ & 440 & 191 & 304 \\
\hline Pichia fermentans & $76-39$ & 326, 299 & 190,175 & 246 \\
\hline Pichia guilliermondii & $05-580$ & 112 & 281 & 390 \\
\hline Pichia guilliermondii & $05-746$ & 112 & 281 & 389 \\
\hline Pichia kluyveri & $53-50$ & 333,357 & $196,182,435$ & $90,255,382,435$ \\
\hline Pichia kluyveri & $65-15$ & 356 & $196,182,435$ & 91,255 \\
\hline Pichia kluyveri var. kluyveri & $40-117$ & 357 & 196 & $91,252,435$ \\
\hline Pichia kluyveri var. kluyveri & $40-324$ & 333,357 & 182,196 & 91 \\
\hline Pichia membranifaciens & $77-100$ & 320,326 & 200 & 255 \\
\hline Pichia membranifaciens & $78-5$ & 320,295 & 200,184 & 256,236 \\
\hline Pichia opuntiae var. thermotolerans & $77-448$ & 460,470 & 460,470 & 460,470 \\
\hline Pichia pinus & $52-84$ & 220 & 420 & $665,167,353$ \\
\hline Pichia populi & $68-628.3$ & 60,455 & 311 & 385 \\
\hline Pichia populi & $68-603$ & 60 & $307,283,314$ & 138,127 \\
\hline Pichia thermotolerans & $80-203$ & 477,320 & 478,320 & 477,320 \\
\hline Rhodotorula glutinis var. glutinis & $40-30$ & 561,640 & 261 & 34,354 \\
\hline Rhodotorula mucilaginosa & $40-141$ & 398 & 55 & 385 \\
\hline Rhodotorula mucilaginosa & $40-188$ & 398 & 55,264 & 385 \\
\hline Saccharomyces bayanus & $74-42$ & 115,125 & 113 & 709 \\
\hline Saccharomyces bayanus & $75-43$ & 126 & 114 & 710 \\
\hline Saccharomyces cerevisiae & $50-149$ & 113,124 & 111 & 709 \\
\hline Saccharomyces cerevisiae & $40-148$ & 124,298 & 112,474 & 710 \\
\hline Saccharomyces cerevisiae & $40-119$ & 114,124 & 112 & 708 \\
\hline Saccharomyces exiguus & $53-63$ & 444,484 & 340 & 450 \\
\hline Saccharomyces exiguus & $40-043$ & 444,484 & 340 & 449 \\
\hline Schizosaccharomyces japonicus var. versatilis & $71-26$ & 149 & 301 & $701,233,380$ \\
\hline Schizosaccharomyces japonicus var. japonicus & $60-255.1$ & 136,149 & 300 & $233,380,611,645$ \\
\hline Schizosaccharomyces pombe & $65-116$ & 411 & 409,499 & 411 \\
\hline Schizosaccharomyces pombe & $70-49$ & 410 & 495 & 409 \\
\hline Sporobolomyces roseus & $67-302$ & 531 & 290 & $119,110,646$ \\
\hline Starmarella bombicola & $62-133$ & 323 & 223 & $270,325,464$ \\
\hline Torulaspora delbrueckii & $40-130$ & 705 & 406 & 705 \\
\hline Torulaspora globosa & $68-37$ & Not detected & 426 & 101 \\
\hline Torulaspora pretoriensis & $61-6$ & 706 & 120,407 & 706 \\
\hline Torulaspora pretoriensis & $66-16$ & 705 & 120,407 & 705 \\
\hline Trichosporon pullulans & $60-83$ & 109 & 40 & 410 \\
\hline Zygoascus hellenicus & $81-681$ & 574,650 & 157 & 644 \\
\hline Zygosaccharomyces bailii & $68-113$ & 83 & 45 & 231 \\
\hline Zygosaccharomyces bailii & $72-1032$ & $\mathbf{8 3}, 158,192$ & 45 & 236 \\
\hline Zygosaccharomyces cidri & $75-9$ & Not detected & 326 & 409 \\
\hline Zygosaccharomyces rouxii & $40-293$ & $476,74,80$ & $340,315,347$ & $874,270,371,728$ \\
\hline Zygotorulaspora florentina & $66-12$ & 600 & 246 & 437 \\
\hline Zygotorulaspora florentina & $67-559$ & 581 & 580 & 440 \\
\hline
\end{tabular}

aFor strain number: VEN denotes UC Davis Viticulture and Enology Culture Collection as source. All others obtained from UC Davis Phaff Yeast Culture Collection.

${ }^{\mathrm{b}}$ Bold type indicates major peak for given restriction digest.

appear only when the associated yeast is highly abundant, as they typically appear at a very low abundance relative to the major TRF, so will not appear under most circumstances.

Most yeasts in the database can be distinguished by the HaeIII restriction digest alone (although all three digests should be performed to confirm findings). In only a few cases are genera/species not distinguished by all three di- gests, as with some closely related species, most notably $S$. cerevisiae and S. bayanus, which cannot be resolved by this technique, and teleomorphs from their anamorphs, such as Candida krusei and Issatchenkia orientalis. However, strains could not be distinguished within species, as demonstrated by analyzing multiple geographically disparate strains of $S$. cerevisiae and C. zemplinina (Table 2), although TRF base 
pair lengths occasionally fluctuate slightly due to run-to-run variation in peak size calling. Within the database, two strains were analyzed for most yeast species, demonstrating the same result in most cases. The only exception was Zygotorulaspora florentina, which displayed high intraspecies heterogeneity, so while the strains tested do have unique TRF profiles, they had divergent TRF profiles for one or more restriction digests, and thus greater diversity may be expected for other strains of this species. However, this isolated example aside, the intraspecies consistency and interspecies separation of other yeasts in the database demonstrate that TRFLP is a robust means of distinguishing genera/species, as strain variation will not result in the detection of unknown peaks.

Although species could be robustly differentiated, a concern with this method was that an overabundance of Saccharomyces in a wine environment would quench the detection of minor yeast populations, thus limiting the sensitivity of this method for profiling complex fermentations. Mixtures of a constant concentration of $S$. cerevisiae $\left(1 \times 10^{7}\right.$ cells/ $\mathrm{mL})$ with serial dilutions of $P$. membranifaciens $\left(1 \times 10^{6}-1\right.$ $\times 10^{2}$ ) were analyzed using TRFLP to determine whether the presence of a majority organism would suppress detection of a minority yeast and to determine the accuracy of the relative quantification provided by this method. The minority yeast, $P$. membranifaciens, could be detected down to $1 \times$ $10^{2}$ cells $/ \mathrm{mL}$ (the detection threshold limit) in the presence of a high concentration of Saccharomyces (Figure 2A, B, C). This limit was separately determined by analyzing serial dilutions of a 1:1 mixture of known cell concentrations of $S$. cerevisiae and P. membranifaciens. Electropherograms of solutions of $1 \times 10^{4}, 1 \times 10^{3}$, and $1 \times 10^{2}$ cells $/ \mathrm{mL}$ were constructed (Figure 2D, E, F), and the latter was determined as the limit of detection, as a $1 \times 10^{1}$ cells $/ \mathrm{mL}$ mixture had no detectable peaks.

To validate this technique and database for describing community structure in actual wine fermentations, TRFLP was

\begin{tabular}{lcc}
\hline \multicolumn{2}{c}{ Table 2 } & Yeast strain consistency trials. \\
\cline { 2 - 3 } Strain number/species & Restriction enzyme \\
\hline 148 S. cerevisiae & $\mathbf{1 2 3}, 298$ & Hhal \\
684 S. cerevisiae & $\mathbf{1 2 3}, 298$ & $\mathbf{1 1 2}, 474$ \\
40-148 S. cerevisiae & 123 & $\mathbf{1 1 2 , 4 7 4}$ \\
40-119 S. cerevisiae & 123 & 112 \\
687 S. cerevisiae & 123 & 112 \\
1332 S. cerevisiae & $\mathbf{1 2 3}, 298$ & 112 \\
04-103 C. zemplinina & 456 & $\mathbf{1 1 2}, 474$ \\
04-112 C. zemplinina & 456 & 234 \\
05-786 C. zemplinina & 456 & 234 \\
06-105 C. zemplinina & 456 & 234 \\
06-143 C. zemplinina & 456 & 234 \\
06-144 C. zemplinina & 456 & 234 \\
06-149 C. zemplinina & 456 & 234 \\
06-150 C. zemplinina & 456 & 234 \\
06-151 C. zemplinina & 456 & 234 \\
\hline
\end{tabular}

aBold values indicate most prominent TRF where multiple values are given. used to study the microbial ecology of a sweet, botrytized wine (Dolce, 2009 vintage, native fermentation) from 0 (press pan sample) through 66 days of fermentation (Figure 3A). Results show that TRFLP could sensitively detect shifts in the populations and could successfully identify most of the organisms present. At crush (time 0 ), the community was dominated by Hanseniaspora spp. (35\% of the relative population) and a TRF profile putatively identified as Botrytis cinerea $(20 \%)$, as well as two other OTUs putatively identified as Penicillium spp. (18\%) and Cladosporium spp. (3\%). These three mold OTUs declined rapidly after fermentation began, as expected. Candida zemplinina, detected only as a trace $(0.3 \%)$ at crush, steadily grew concurrent with the decreasing population of Hanseniaspora. By day 32, C. zemplinina surpassed Hanseniaspora as the dominant yeast present and constituted $42 \%$ of the population at day 66. Saccharomyces only appeared at day 26 ( $1 \%$ relative population) and quickly grew from there, constituting $37 \%$ of the population at day 49 , existing briefly as the most dominant yeast, but only $21 \%$ of the population at day 66. Metchnikowia pulcherrima, Candida lactis-condensi, and Pichia angophorae were also detected at low levels $(<20 \%$ combined) fluctuating throughout the monitoring period.



Figure 2 Electropherograms of decreasing cell concentrations of $P$. membranifaciens titrated against a known concentration of $S$. cerevisiae: (A) $10^{7}: 10^{6}$ cells $/ \mathrm{mL}$ (S. cerevisiae : P. membranifaciens); (B) $10^{7}: 10^{4}$ cells $/ \mathrm{mL}$; (C) $10^{7}: 10^{2}$ cells $/ \mathrm{mL}$. Electropherograms of decreasing cell concentrations of a $1: 1$ mixture of $S$. cerevisiae : $P$. membranifaciens, demonstrating TRFLP detection limit: (D) $1 \times 10^{4}$ cells $/ \mathrm{mL}$; (E) $1 \times 10^{3}$ cells $/ \mathrm{mL}$; (F) $1 \times 10^{2}$ cells $/ \mathrm{mL}$ (S.c.: Saccharomyces cerevisiae; P.m.: Pichia membranifaciens). 
Previous analysis of an earlier vintage of the Dolce fermentation revealed dominance of Saccharomyces (Mills et al. 2002). To confirm the relative populations of C. zemplinina and S. cerevisiae observed in 2009 using TRFLP (early dominance of C. zemplinina and late appearance of Saccharomyces), we used qPCR to detect total yeast, C. zemplinina, and Saccharomyces spp. (Figure 4A). Total yeast cell concentrations gradually declined from a maximum of $9.1 \times 10^{6}$ cells/ $\mathrm{mL}\left( \pm 7.7 \times 10^{5}\right)$ at day 0 to $4.7 \times 10^{4}$ cells $/ \mathrm{mL}\left( \pm 5.4 \times 10^{3}\right)$ by week 66 . This qPCR assay, designed to quantify wine yeasts by targeting a section of the D1/D2 loop of the $26 \mathrm{~S}$ rRNA gene (Hierro et al. 2006) most likely detects molds and other similar fungi as well, hence the maximal detection at crush (parallel with the mold-associated TRFs detected by TRFLP). Total Saccharomyces, in turn, were detected at $8.1 \times 10^{2} \pm 1.4 \times 10^{2}$ cells $/ \mathrm{mL}$ at crush and remained at these levels for the first 2 weeks $\left(1.8 \times 10^{3} \pm 1.8 \times 10^{1}\right.$ cells $/ \mathrm{mL}$ at day 10). Only at day 17 did this yeast reach a concentration of $2.0 \times 10^{5}$ cells $/ \mathrm{mL}\left( \pm 1.4 \times 10^{2}\right)$, less than $5 \%$ of the total yeast present. Saccharomyces peaked at $1.3 \times 10^{6}$ cells $/ \mathrm{mL}$ $\left( \pm 4.1 \times 10^{4}\right)$ at day $32(\sim 50 \%$ of the total yeast $)$ and declined thereafter, remaining at $\sim 50$ to $75 \%$ of the total yeast population detected. C. zemplinina, on the other hand, was detected at higher levels at crush $\left(2.4 \times 10^{3} \pm 1.7 \times 10^{4}\right.$ cells $\left./ \mathrm{mL}\right)$ and increased from there to peak at $7.8 \times 10^{5}\left( \pm 4.9 \times 10^{4}\right)$ cells/ $\mathrm{mL}$ at day 26. After day 26, this population remained stable as the total yeast count fell, accounting for a greater proportion of the yeast community from days 32 to 66 . After day 49, the population continued to decline, while remaining at $\sim 50 \%$ of the total yeast count. Brix gradually fell from 34 Brix at crush to 13.25 Brix at day 66 (Figure 4B). By the time Saccharomyces emerged at day 17 , the fermentation had already reached 19.5 Brix.

A second vintage (2008, inoculated with a strain of S. cerevisiae) of the Dolce fermentation was analyzed using TRFLP, demonstrating the robust ability of this technique for describing community shifts in large-scale, vertical and lateral studies. Results show a similar cast of yeasts as observed in the 2009 vintage (Figure 3B). Two separate press pan samples (representing grapes from two different vineyards blended prior to fermentation) were tested, indicating a large presence of B. cinerea (33-37\%), M. pulcherrima (14-38\%), Hanseniaspora (3-37\%), and C. zemplinina (1-11\%) but no Saccharomyces. On pumping from the press pan, all samples were inoculated with $S$. cerevisiae, hence the sudden dominance of this yeast at day 1 (44\%). Botrytis cinerea, Hanseniaspora,
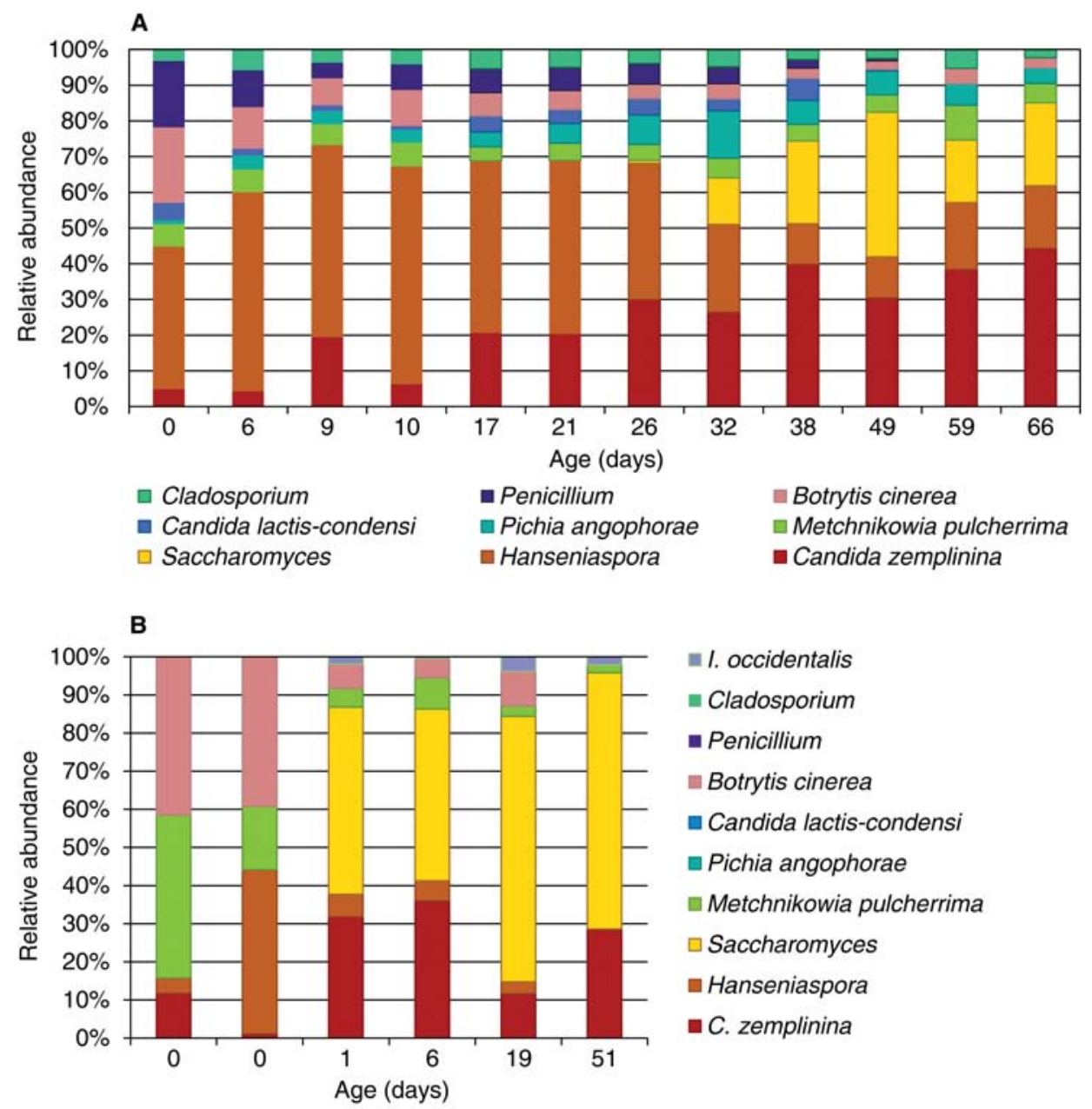

Figure 3 Relative populations of yeasts identified in the Dolce fermentation over time determined by TRFLP. Relative populations are determined as ratios of specific peak fluorescence to total filtered peak fluorescence. All samples were tested in duplicate and data are average values. (A) 2009 vintage; (B) 2008 vintage. 
and M. pulcherrima constituted minor constituents from day 1 through day 51, but C. zemplinina still thrived in this fermentation even following inoculation, growing to $28 \%$ of the total population at day 1 and fluctuating from 11 to $34 \%$ of the total population through day 51. Issatchenkia occidentalis was also found at very low levels $(0.4-3.0 \%)$ in this vintage from day 1 through 51 (but not in the press pan).

qPCR was again used to confirm the relative populations of yeasts observed using TRFLP, and corroborated this trend (Figure $4 \mathrm{C}$ ), detecting $2.7 \times 10^{7}$ cells $/ \mathrm{mL}\left( \pm 1.0 \times 10^{6}\right)$ of total yeasts in one of the press pan samples, but only $3.2 \times 10^{3}$ cells $/ \mathrm{mL}\left( \pm 6.0 \times 10^{1}\right)$ of Saccharomyces. Following inoculation, total yeasts remained $>10^{7}$ cells $/ \mathrm{mL}$ through day $6, \sim 50 \%$ of which was Saccharomyces, before dropping into the $10^{6}$ cells $/ \mathrm{mL}$ range from day 19 through 51. Saccharomyces was detected at $28 \%$ of the total population at day 19 and $60 \%$ at day 51. Candida zemplinina was detected at $4.6 \times 10^{4}$ cells/ $\mathrm{mL}\left( \pm 1.6 \times 10^{2}\right)$ in the press pan and increased dramatically to $1.4 \times 10^{6}$ cells $/ \mathrm{mL}\left( \pm 2.9 \times 10^{4}\right)$ after day 1 of fermentation. After day 1, this population slowly declined, but remained a significant contingent of the yeast community, detected at 3.0 $\times 10^{5}$ cells $/ \mathrm{mL}\left( \pm 2.0 \times 10^{3}\right)$ on day 51 . The sugar concentration measured at crush was 36 Brix and, after six days of lag, gradually declined to a final concentration of 12.25 Brix (Figure 4D).
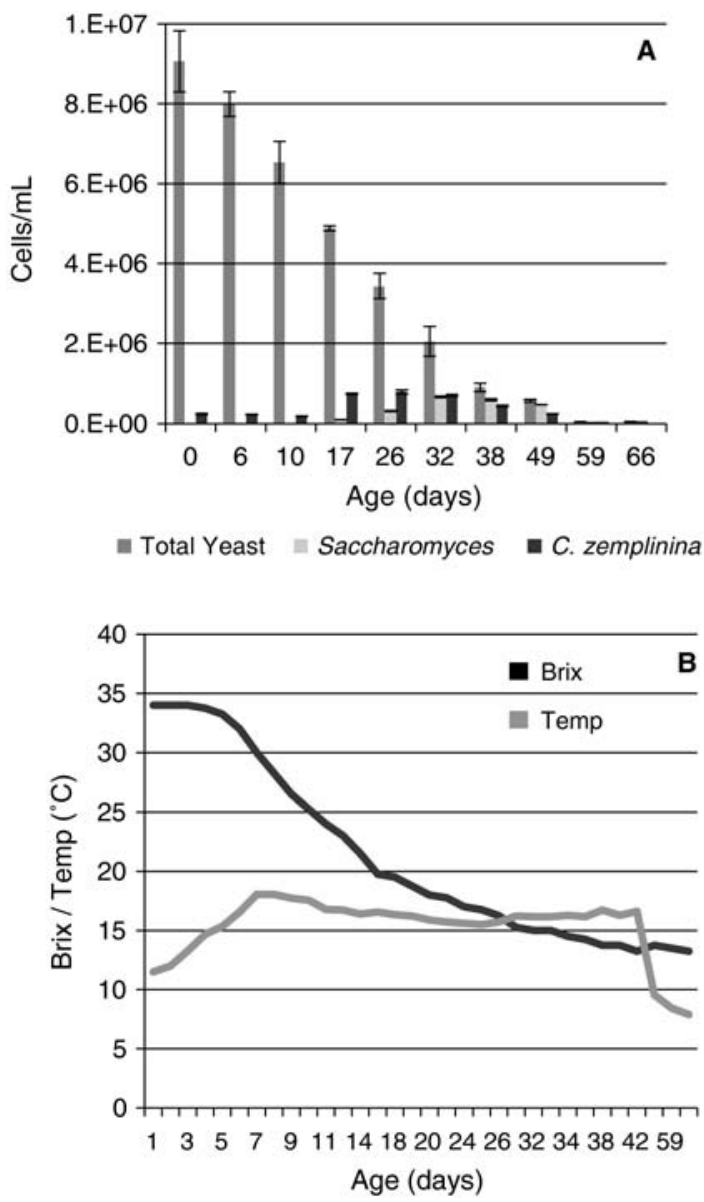

\section{Discussion}

The yeast TRFLP database described in this work was a necessary prerequisite for the application of TRFLP for accurate identification of yeasts in wine and, indeed, any other environment, due to the lack of yeast ITS sequence data deposited in public databases and to the inclusion of numerous, variable ITS copies within the genomes of individual yeast strains, leading to a disparity between empirical TRF patterns and in silico predictions (Anderson and Cairney 2004). The ITS spacers are noncoding regions, accumulating mutations more quickly than vital coding regions, such as the flanking $18 \mathrm{~S}$ and $26 \mathrm{~S}$ rRNA genes that are also commonly used for identification of fungal isolates. For this reason, the ITS region was chosen as a target for this TRFLP assay, as the $18 \mathrm{~S}$ and $26 \mathrm{~S}$ rRNA are not sufficiently divergent to allow restriction-enzyme-based discrimination of closely related yeast species using TRFLP. As shown in this work, the ITS region presents an optimal site for TRFLP analysis, containing enough intraspecies similarity to afford reliable identification but enough intragenus heterogeneity to effectively separate most genera into species.

The molds detected in the 2009 vintage Dolce fermentation, B. cinerea, Penicillium sp., and Cladosporium sp., were putatively identified via in silico predictions based on restriction mapping, the same approach used for OTU identification
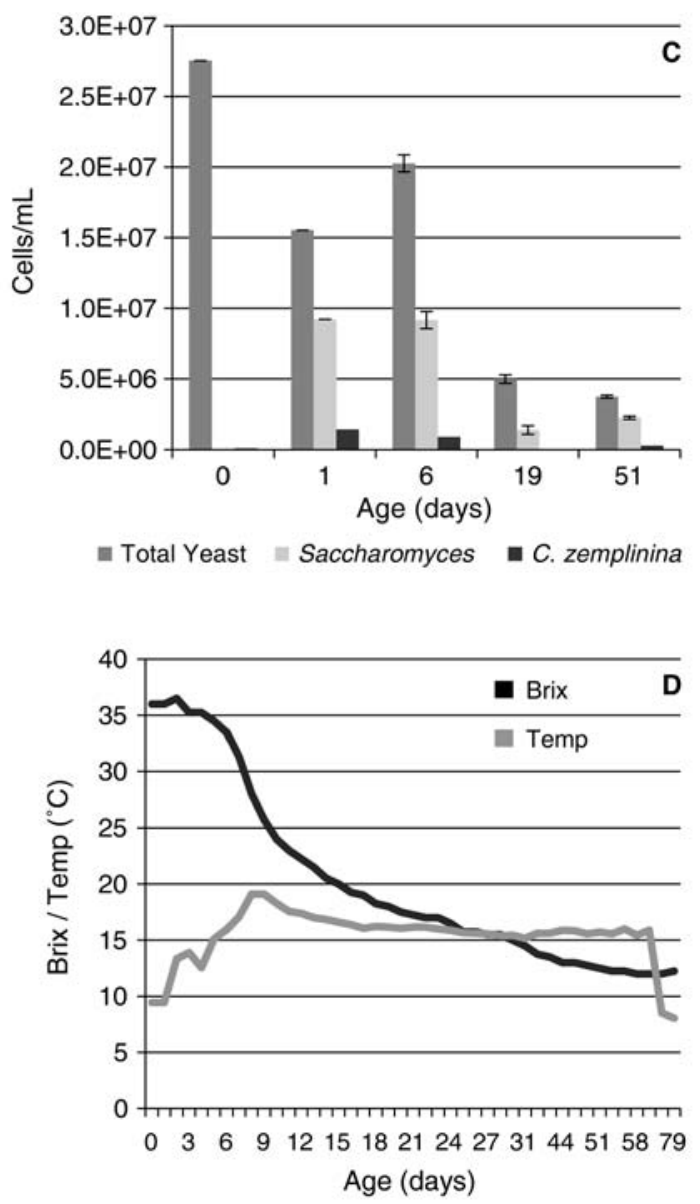

Figure 4 Quantitative PCR of Dolce fermentation over time in 2009 (A) and 2008 (C). All samples were tested in triplicate and their mean values ( \pm standard deviation) are presented. Brix and temperature measurements for the 2009 (B) and 2008 (D) vintages. 
of bacterial TRF profiles (Liu et al. 1997). The TRF profiles associated with these molds were abundant at crush (together $\sim 42 \%$ of the total population) but rapidly diminished once fermentation began. However, even though no other taxonomic group could be matched to these TRF profiles, these are not definitive identification, as these organisms are not present in the ITS TRFLP database. This database was initially constructed to identify only organisms actively involved in wine fermentations; as most molds and nonfermentative yeasts presumably go dormant/die once grapes are crushed, fermentation begins, and oxygen availability declines, they were not considered in this category and were not included in the database. This is one major limitation of the current method, which will be corrected as the database continues to expand.

Although TRF abundance has been shown to correlate strongly with relative population abundance within a sample (Lueders and Friedrich 2003), giving a reproducible perspective of community structure (pseudo-quantitatively), it should not be assumed that TRFLP can be used as a stand-alone method for absolute cell quantification. Like any PCR-based method, TRFLP is prone to errors such as primer binding bias (mitigated by combined, replicate PCRs and increased DNA template concentration; Polz and Cavanaugh 1998) and copy number heterogeneity (Crosby and Criddle 2003), which can skew the apparent abundance of community members. Reliable quantification requires the use of qPCR or other quantitative methods targeting populations of interest identified by TRFLP data. Thus, qPCR was used to confirm the accuracy of the pseudo-quantitative TRFLP results, specifically the relative populations of $S$. cerevisiae and C. zemplinina, the most abundant yeasts observed. As presented above, qPCR recovered relative population abundance data comparable to those revealed by TRFLP, indicating that TRFLP can reliably represent yeast community structure in wine. These data correlate fairly well with studies of older vintages of the Dolce fermentation using DGGE (Cocolin et al. 2001, Mills et al. 2002), in which C. zemplinina was the dominant yeast throughout the early fermentation and persisting throughout, with $S$. cerevisiae starting to appear only later in the fermentation. However, this vintage (2009) displayed a much more dominant population of C. zemplinina and much less prominent population of $S$. cerevisiae than previous years, as shown by both TRFLP and qPCR.

There is abundant enology research using culture-dependent methods to describe complex fermentation communities and enological treatments. Such methods are innately problematic, biasing for those organisms which are best cultured in the microbiological medium of choice. Additionally, they can be extremely time-consuming and laborious, typically requiring a molecular method for identification of an organism once it is fully cultured. Over the past decade, molecular profiling methods have slowly gained recognition for their greater power, speed, and accuracy for enology studies compared to traditional methods, although they are not without their own flaws and the most current methods are often prohibitively expensive for such studies. This is where TRFLP can prove advantageous as a rapid, culture-independent, sensitive, and above all low-cost technique for yeast community profiling. TRFLP is not an error-free method, but this method would be beneficial applied to small- and large-scale studies involving time- and/or treatment-based variables because of its low cost and adaptability for high-throughput processing. Expansion of the database to include yeasts common to other fermentations would enable adaptation to almost any food or beverage scenario. Indeed, with appropriate additions to the database this method could be used to profile fungal communities in almost any environment, such as clinical or host-associated specimens. Grape- and vine-associated fungi could also be added to enable analysis of viticultural specimens, such as vine/berry surface microbiota or grapevine pathogens.

A key attribute of this method is its technical ease, relying on basic research laboratory procedures and tools, namely PCR and restriction digests, to generate data, so could be performed with access to a PCR thermal cycler. Subsequent analysis is carried out at standard DNA sequencing facilities (routinely available) for fragment size determination. In this regard, TRFLP could be integrated at wine-testing service laboratories and could even be applied at wineries capable of performing PCR and with external access to commercial fragment analysis. The capacity of this technique for sensitively identifying complex, mixed microbiota may be useful in commercial scenarios, enabling detection of potential spoilage organisms. TRFLP is best used for resolving mixed culture fermentations, but could even be applied to spoilage yeast detection in finished wines, especially if the microbiological status is unknown and multiple contaminants may be present (a possibility in unfiltered wines). This would enable detection and identification of microbes without time-consuming culturing and isolation steps. qPCR is better suited for enumeration of specific, targeted organisms (e.g., if Brettanomyces is the only contaminant of interest), but, while more quantitatively accurate, will miss those populations not targeted. Therefore, pairing qPCR with a community profiling method such as TRFLP provides a mechanism for catching the "missed" populations in a standard qPCR analysis.

\section{Conclusion}

TRFLP presents a valuable technique for profiling the yeast community of wine and other fermentations. This method, using the database described herein, can sensitively distinguish multiple populations in wine and their relative population sizes. TRFLP is a rapid, powerful, pseudo-quantitative technique for revealing community structure in complex, mixed-microbial fermentations and can detect minor populations in diverse, complex fermentations to a relatively low limit of detection $\left(1 \times 10^{2}\right.$ cells $\left./ \mathrm{mL}\right)$. The speed, low cost, and sensitivity of this technique makes it a promising option for community profiling of wine and other fermentations, with direct applications to commercial wine-testing scenarios and to enological and viticultural research.

\section{Literature Cited}

Abdo, Z., U.M.E. Schuette, S.J. Bent, C.J. Williams, L.J. Forney, and P. Joyce. 2006. Statistical methods for characterizing diversity 
of microbial communities by analysis of terminal restriction fragment length polymorphisms of 16S rRNA genes. Env. Microbiol. 8(5):929-938.

Adams Krumins, J., J. Dighton, D. Gray, R.B. Franklin, P.J. Morin, and M.S. Roberts. 2009. Soil microbial community response to nitrogen enrichment in two scrub oak forests. For. Ecol. Manage. 258:1383-1390.

Anderson, I.C., and J.W.G. Cairney. 2004. Diversity and ecology of soil fungal communities: Increased understanding through the application of molecular techniques. Env. Microbiol. 6(8):769-779.

Blackwood, C.B., T. Marsh, S.H. Kim, and E.A. Paul. 2003. Terminal restriction fragment length polymorphism data analysis for quantitative comparison of microbial communities. Appl. Environ. Microbiol. 69:926-932.

Boulton, R.B., V.L. Singleton, L.F. Bisson, and R.E. Kunkee. 1996. Principles and Practices of Winemaking. Chapman \& Hall, New York.

Cocolin, L., L.F. Bisson, and D.A. Mills. 2000. Direct profiling of yeast dynamics in wine fermentations. FEMS Microbiol. Lett. 189:81-87.

Cocolin, L., A. Heisey, and D.A. Mills. 2001. Direct identification of the indigenous yeasts in commercial wine fermentations. Am. J. Enol. Vitic. 52:49-53.

Crosby, L.D., and C.S. Criddle. 2003. Understanding bias in microbial community analysis techniques due to $r r n$ operon copy number heterogeneity. Biotechniques 34:790-802.

Edwards, I.P., and D.R. Zak. 2010. Phylogenetic similarity and structure of Agaricomycotina communities across a forested landscape. Mol. Ecol. 19:1469-1482.

Gardes, M., and T.D. Bruns. 1993. ITS primers with enhanced specificity for basidiomycetes-application to the identification of mycorrhizae and rusts. Mol. Ecol. 3:113-118.

Heard, G.M., and G.H. Fleet. 1986. Evaluation of selective media for enumeration of yeasts during wine fermentation. J. Appl. Bacteriol. 60:477-481.

Hierro, N., B. Esteve-Zarzoso, A. Gonzalez, A. Mas, and J.M. Guillamon. 2006. Real-time quantitative PCR (QPCR) and reversetranscription-QPCR for detection and enumeration of total yeasts in wine. Appl. Environ. Microbiol. 72:7148-7155.

Kisand, V., and J. Wikner. 2003. Limited resolution of 16S rDNA DGGE caused by melting properties and closely related DNA sequences. J. Microbiol. Meth. 54:183-191.

Liu, W., T.L. Marsh, H. Cheng, and L.J. Forney. 1997. Characterization of microbial diversity by determining terminal restriction fragment length polymorphisms of genes encoding 16S RNA. Appl. Environ. Microbiol. 63:4516-4522.

Lueders, T., and M.W. Friedrich. 2003. Evaluation of PCR amplification bias by terminal restriction fragment length polymorphism analysis of small-subunit rRNA and mcrA genes by using defined template mixtures of methanogenic pure cultures and soil DNA extracts. Appl. Environ. Microbiol. 69:320-326.

Macdonald, L.M., B.K. Singh, N. Thomas, M.J. Brewer, C.D. Campbell, and L.A. Dawson. 2008. Microbial DNA profiling by multiplex terminal restriction fragment length polymorphism for forensic comparison of soil and the influence of sample condition. J. Appl. Microbiol. 105:813-821.

Millet, V., and A. Lonvaud-Funel. 2000. The viable but non-culturable state of wine micro-organisms during storage. Lett. Appl. Microbiol. 30:136-141.

Mills, D.A., A.J. Eric, and L. Cocolin. 2002. Yeast diversity and persistence in botrytis-affected wine fermentations. Appl. Environ. Microbiol. 68:4884-4893.

Nubel, U., B. Engelen, A. Felske, J. Snaidr, A. Wieshuber, R.I. Amann, W. Ludwig, and H. Backhaus. 1996. Sequence heterogeneities of genes encoding 16S rRNA in Paenibacillus polymyxa detected by temperature gradient gel electrophoresis. J. Bacteriol. 178:5636-5643.

Osborn, A.M., E.R.B. Moore, and K.N. Timmis. 2000. An evaluation of terminal-restriction fragment length polymorphism (T-RFLP) analysis for the study of microbial community structure and dynamics. Environ. Microbiol. 2:39-50.

Polz, M.F., and C.M. Cavanaugh. 1998. Bias in template-to-product ratios in multitemplate PCR. Appl. Environ. Microbiol. 64:3724-3730.

Schutte, U.M., Z. Abdo, S.J. Bent, C. Shya, C.J. Williams, J.D. Pierson, and L.J. Forney. 2008. Advances in the use of terminal restriction fragment length polymorphism (T-RFLP) analysis of 16S rRNA genes to characterize microbial communities. Appl. Microbiol. Biotechnol. 80:365-380.

Sekiguchi, H., N. Tomioka, T. Nakahara, and H. Uchiyama. 2001. A single band does not always represent single bacterial strains in denaturing gradient gel electrophoresis analysis. Biotechnol. Lett. 23:1205-1208.

Trotha, R., U. Reich, F.L. Thies, D. Sperling, W. Konig, and B. Konig. 2002. Adaption of a fragment analysis technique to an automated high-throughput multicapillary electrophoresis device for the precise qualitative and quantitative characterization of microbial communities. Electrophoresis 23:1070-1079.

White, T., T. Burns, S. Lee, and J. Taylor. 1990. Amplification and direct sequencing of fungal ribosomal RNA genes for phylogenetics. In PCR Protocols. A Guide to Methods and Applications. M.A. Innis, et al. (eds.), pp. 315-322. Academic Press, San Diego.

Zott, K., O. Claisse, P. Lucas, L.J. Coulon, A. Lonvaud-Funel, and I. Masneuf-Pomerade. 2010. Characterization of the yeast ecosystem in grape must and wine using real-time PCR. Food Microbiol. 27:550-567. 